\title{
A MANAGEMENT DECISION TOOL FOR MINK (Mustela vison) CONTROL IN THE WESTERN ISLES OF SCOTLAND (UK)
}

\author{
F.J. AREAL ${ }^{1} \&$ S.S. ROY 2 \\ ${ }^{1}$ Department of Agricultural and Food Economics, The University of Reading, UK. \\ ${ }^{2}$ Central Science Laboratory, Sand Hutton, York, UK.
}

\begin{abstract}
Dynamic ecological-economic modelling was used to conduct a comprehensive analysis of the economic impacts of the American mink (Mustela vison) on a marketable, exploitable, native species Salmon (Salmo salar) reared in fish farms in the Western Isles. A cost-benefit analysis of the different mink control options, including a 'doing nothing' option as a baseline, was conducted. Biological and economic data as well as the assumptions used in the simulations are based on scientific literature and from a 5-year mink control project on the Western Isles. Results suggest mink eradication as the best long-term strategy for an isolated fish farm being affected by predation. However, 'doing nothing' would be the best option if average market prices for farmed salmon are low over a long period of time and/or the pest control manager overestimates the area being impacted by mink.
\end{abstract}

Keywords: control, cost-benefit analysis, farmed salmon, mink, simulation modelling.

\section{INTRODUCTION}

Invasive species are considered to be the second most important cause of biodiversity loss worldwide $[1,2]$, and are also responsible for substantial economic losses to agri-environmental systems [3, 4].

This study presents a dynamic ecological-economic model that served to establish the most costeffective alternative for predator control. This model takes into account the economic effect of a predator (i.e. mink) on an economically exploitable species (i.e. farmed salmon) under a number of predator control strategies a salmon fish farm has.

Managing vertebrate pests in agricultural systems has only recently grown as a research topic in the agricultural sciences, and to date the economic analysis of vertebrate pest control has been the result of reactionary rather than preventative management decisions [5]. Scenarios where economic analysis often drives or is incorporated into pest control management decisions have to date involved mostly invertebrate pests and crops [6]. There are few examples where the same approach has been applied to vertebrate pests [7-9]. Most of these examples involve simple, yet effective, LotkaVolterra models where the effects of predator removal on prey populations, and the cost of that predator removal can be incorporated into a cost-benefit analysis (CBA) to aid decision-making [7]. Other good examples of studies incorporating economic and ecological modelling to optimise the management strategies of a vertebrate pest are given by Moberly et al. [9] where the costs of different control strategies of wild foxes are balanced through a process of combining decision theory, marginal analysis and relating the costs associated with predation losses to expenditure on preventive measures to avoid fox predation on lambs on sheep farms in the UK. However, there are few examples that involve long-term strategies based on discounted estimates of profits and loss, market prices together with long-term changes in the predator or pest population. There are few examples where this work has been carried out for fish farms, especially with mammalian predators. Where work has been carried out on fish farms, the modelling has been ecological, rather than economic, and has involved culling species such as piscivorous birds rather than mammals [10].

The Western Isles form an archipelago on the north-west coast of Scotland that occupies only $1 \%$ of the UK landmass $\left(2800 \mathrm{~km}^{2}\right)$, yet has $15 \%$ of its surface area of freshwater, which together with

(C) 2009 WIT Press, www.witpress.com

ISSN: 1755-7437 (paper format), ISSN: 1755-7445 (online), http://journals.witpress.com

DOI: $10.2495 / \mathrm{DNE}-\mathrm{V} 4-\mathrm{N} 1-16-31$ 


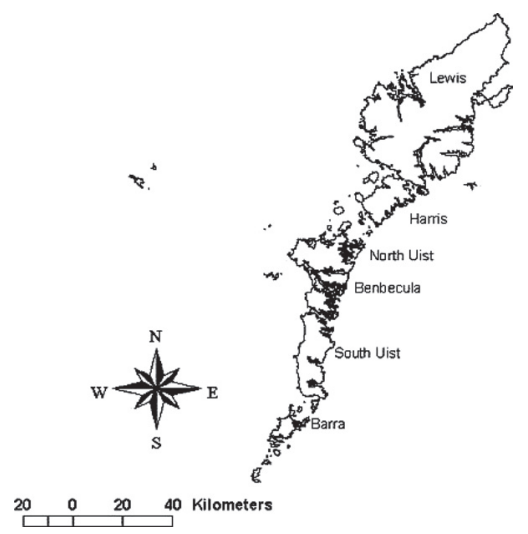

Figure 1: Western Isles.

its large and easily accessed coastline make it ideal for farming fish species that require both fresh water and marine environments for development [11]. The Western Isles comprise five main islands: Lewis and Harris, North Uist, Benbecula, South Uist and Barra (Fig. 1).

Salmon production in Scotland began in the 1960s and has since increased rapidly, particularly in the last two decades, with production ranging from 6900 tonnes in 1985 to over 130000 tonnes in 2000 [12]. The salmon farming industry is also highly restricted to a few companies. Currently, there are totally 15 companies operating in the Western Isles representing 94 fish farms of which 88 exclusively produce salmon [11]. Three companies accounted for more than $70 \%$ of the salmon production in the year (Table 1). The average salmon production is 624 tonnes (SD 406 tonnes) per year with a maximum production of 2000 tonnes and a minimum of 20 tonnes.

The American mink (Mustela vison) have spread throughout the Western Isles, following their escape from three fur farms in the 1960s [13]. Feral mink populations became established in the 1960s in Lewis, and by the 1980s had reached South Harris. Despite attempts to stop the spread, the species spread to the Uists in the 1990s [14] and populations were discovered in South Uist by 2000 [15].

Mink population dynamics in the Western Isles have been investigated during and following culling operations conducted in the region in the mid-1980s [14] and more recently [15-17]. Helyar [17] studied the effects of density reduction on the dynamics of a previously partially controlled population and a heavily controlled population of mink. Control was found to have a density-dependent effect on mink survival rates; there was no significant effect on immigration and emigration; and no density-dependent effect on individual productivity per female as found from the number of active teats [18].

Mink diet is broad and varies considerably between habitats. They have been recorded preying on fish, crustaceans, birds (eggs, young and adults), small mammals, amphibians, insects and carrion [19-26]. The diet of mink in the Western Isles is largely reliant on aquatic prey, particularly crustaceans and small fish, and varies between different areas within the Western Isles [11]. A total of 15.9\% of mink diet from April 2002 to November 2004 in the Western Isles was found to be fish but seasonal variation resulted in the biomass of fish consumed being highest in spring (25\%), which then decreased through the rest of the year.

Mink have the potential to cause important economic losses to all outdoor fish farms, including salmon fish farms as Atlantic salmon and brown trout can be a prominent food source for mink in 
Table 1: Annual production of salmon (tonnes) by fish farm companies in the Western Isles (2002).

\begin{tabular}{lrr}
\hline Company & Production & \multicolumn{1}{c}{$\%$} \\
\hline Abinaban Salmon & 20 & 0.0 \\
Angus Macmillan & 900 & 1.8 \\
Atlantic West Salmon & 1550 & 3.1 \\
Bratan Baghasdal Ltd. & 600 & 1.2 \\
Carloway Seafoods Ltd & 3750 & 7.6 \\
Gaelic Seafoods & 240 & 0.5 \\
Hebridean Fishery & 3950 & 8.0 \\
Lewis Salmon Ltd & 500 & 1.0 \\
Marine Harvest (Scotland) Ltd & 13752 & 27.9 \\
North Uist Fisheries & 26 & 0.1 \\
Salar Ltd & 800 & 1.6 \\
Sidinish Salmon & 900 & 1.8 \\
Stolt Sea Farms Ltd & 12540 & 25.4 \\
West Minch Salmon & 1366 & 2.8 \\
Wisco & 8430 & 17.1 \\
Total & 49,324 & 100.0 \\
\hline
\end{tabular}

inland habitats during the winter and spring [27, 28]. They can also cause significant infrequent damage to equipment. A good example of this was recorded in 1988, when 14500 smolts were reported to have escaped from a salmon farm as a result of mink damage to rearing nets, costing $£ 11600$ [29].

A large-scale project was set up in November 2001, funded by the European Union (EU) Life Programme and a consortium of local government and non-government organisations, to eradicate mink from the Uists [15]. Live-capture wire cage traps are laid out over large areas along watercourses and coastlines approximately $200-400 \mathrm{~m}$ apart, baited and checked daily. This project has now come to a close with the successful removal of 532 mink from Harris and the Uists [30]. Parameters from this project have been used in the modelling study detailed in this paper.

\section{METHODS}

A model was developed to analyse the economic viability of different control strategies for mink populations affecting salmon production in fish farms. The model incorporates mink and salmon population dynamic parameters in the Western Isles (UK). The model was built using Vensim 5.5 software (Ventana Systems, Inc., Harvard, USA).

Biological and economic data as well as the assumptions used in the simulations are based on previous work in the Western Isles and the West coast of Scotland [17, 19, 29-32]. Where data were not available, or the values of input variables were uncertain, estimates were made using the best available data or expert judgement through interviews conducted with fishfarms in the region.

The overall computational model is described in Table 2 and Figs 2 and 3. The model describes the salmon production in a farm being negatively affected by mink population and the costs associated with both the control strategy selected by the manager and the costs associated with the damage caused by the mink population on farmed salmon. Costs associated with the strategy chosen are 
Table 2: Parameters and equations of the model.

\begin{tabular}{|c|c|c|}
\hline Parameter & Units & Model formula and parameter setting \\
\hline Female salmon & Number & 50 \\
\hline Salmon eggs & Number & $\begin{array}{l}\text { Female salmon } \times \text { RANDOM UNIFORM }(4500,5200,0) \text {; } \\
\text { Willoughby [33] }\end{array}$ \\
\hline Fry & Number & Salmon eggs $-($ Salmon eggs $\times$ fry mortality rate $)$ \\
\hline Fry mortality rate & Rate & RANDOM UNIFORM $(0.1,0.15,0)$ \\
\hline Parr & Number & Fry-(fryxparr mortality rate) \\
\hline Parr mortality rate & Rate & RANDOM UNIFORM $(0.1,0.2,0)$ \\
\hline Smolts & Number & (parr-(parr×smolt mortality rate))-(Total Damage) \\
\hline Smolt mortality rate & Rate & RANDOM UNIFORM $(0.15,0.2,0)$ \\
\hline Total damage & Number & (Mink population×Individual damage) \\
\hline Individual damage & Number & $\begin{array}{l}\text { 4380/RANDOM TRIANGULAR }(20,150,20,60,150,0) \text {; } \\
\text { Heylar [11] }\end{array}$ \\
\hline Adult salmon production & Tonnes & Smolts $\times$ adult weight \\
\hline Adult weight & Tonnes & $\begin{array}{l}\text { RANDOM TRIANGULAR }(0.0025,0.005,0.0025,0.004 \text {, } \\
0.005,0)\end{array}$ \\
\hline Salmon output value & $£$ & Salmon market pricex(Adult salmon production) \\
\hline Salmon market price & $£ /$ tonne & $(2000,1000,3000)$ \\
\hline Mink population & Number & Mink population growth rate-Control method \\
\hline Mink population growth & Rate & $r \times$ Mink population $\times(1-($ Mink population $/ K))$ \\
\hline$r$ & Rate & $(0.38,0.46)$; Clode et al. $[34]$ \\
\hline K & Number & Area infected $\mathrm{km}^{2} \times 1.6$ \\
\hline Area infected & $\mathrm{km}^{2}$ & $(15,30,45)$ \\
\hline Cost caused by pest & $£$ & Total DamagexSalmon market pricexadult weight \\
\hline Control costs & $£$ & (Capital costs+operational costs) \\
\hline Capital costs & $£$ & $\begin{array}{l}\text { IF THEN ELSE(Mink population }>0 \text { :AND: } \\
\text { Control method }>0 \text { :AND:Time }=\text { start, vehicles+trap } \\
\text { price } \times \text { number of traps+staff equipment, } 0 \text { ) }\end{array}$ \\
\hline Vehicles & $£$ & 40000 \\
\hline Trap price & $£$ & 12 \\
\hline Staff equipment & $£$ & 600 \\
\hline Number of traps & $£$ & $5 \times$ area covered $\mathrm{km}^{2}$ \\
\hline Area covered $\left(\mathrm{km}^{2}\right)$ & ha & 5 \\
\hline Level & Number & Catchability ratexnumber of traps $x$ days \\
\hline Catchability rate & Rate & $(0.001 ; 0.00196 ; 0.0028 ; 0.00364)$ \\
\hline Start & Year & $(1, . ., 10)$ \\
\hline Duration & Year & $(1, \ldots, 19)$ \\
\hline Control method (a) & Number & (level×PULSE(start,duration)) \\
\hline Control method (b) & Number & (level×PULSE TRAIN (start,duration,5,FINAL TIME)) \\
\hline Operational costs & $£$ & $\begin{array}{l}\text { IF THEN ELSE(Control method }>0 \text {, maintenance and } \\
\text { fuel } \times \text { days+staff } \times \text { staff wages } \times \text { days, } 0 \text { ) }\end{array}$ \\
\hline Maintenance and fuel & $£ /$ day & RANDOM UNIFORM $(25,43.5,45)$ \\
\hline Staff wages & $£ /$ day & 46 \\
\hline
\end{tabular}


Table 2: Continued

\begin{tabular}{lll}
\hline Parameter & Units & Model formula and parameter setting \\
\hline Staff & Number & 1.5 \\
Days & Number & 108 \\
Present cost & $£$ & NPVE(Cost caused by pest+control costs, discount \\
& & rate $, 0,1)$ \\
Discount rate & Rate & 0.025 \\
\hline
\end{tabular}

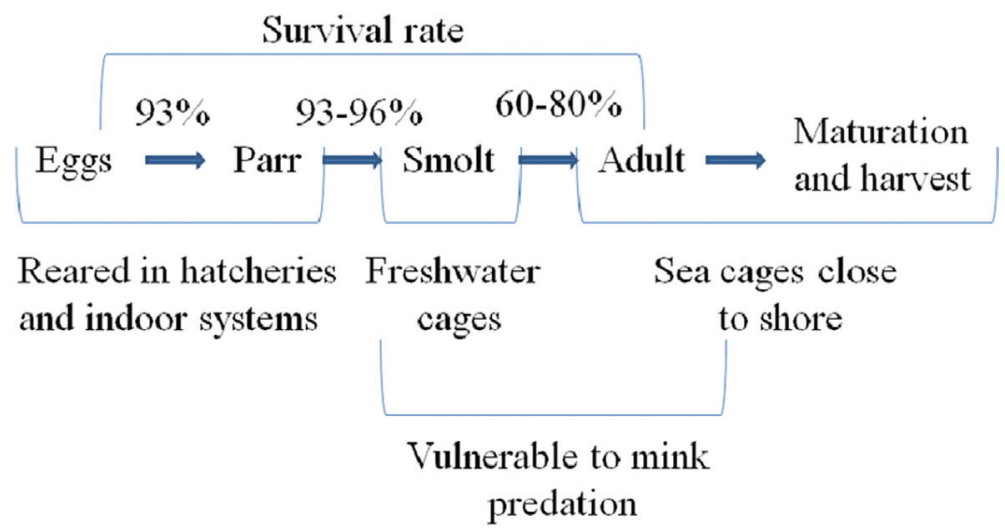

Figure 2: Salmon life cycle.

called 'control costs' and are split into operational and capital costs. These costs depend on the control strategy chosen by the manager (see Section 2.2 to see the different strategies and Table 3 for the costs linked to mink control strategy). Costs related to mink preying on farmed salmon depend on the quantity of salmon preyed by the mink population per year and the market price of farmed salmon is evaluated at farmed salmon market prices. Finally, control costs and costs linked to farmed salmon predation from mink are added to calculate the net present cost. In order to compare the costs of different control strategies we run the model for each mink control strategy. In order to calculate the benefits related to implementing a control strategy we calculate the difference between the costs related to mink preying on farmed salmon under 'no control' strategy and each of the strategy where some type of mink control is implemented. Models were run for a timescale of 30 years in order to take into account the following factors: (i) control options are multi-period investment projects and (ii) the posterior effects of those options on mink population and the consequent damage on the fish farm. Thus, such a time scale allows us to examine how net benefits of implementing a control strategy vary over this period. This study does not use the conventional predator-prey model [i.e. Lotka-Volterra type model described in eqns (1) and (2)].

$$
\frac{\mathrm{d} x}{\mathrm{~d} t}=x(\alpha-\beta y)
$$




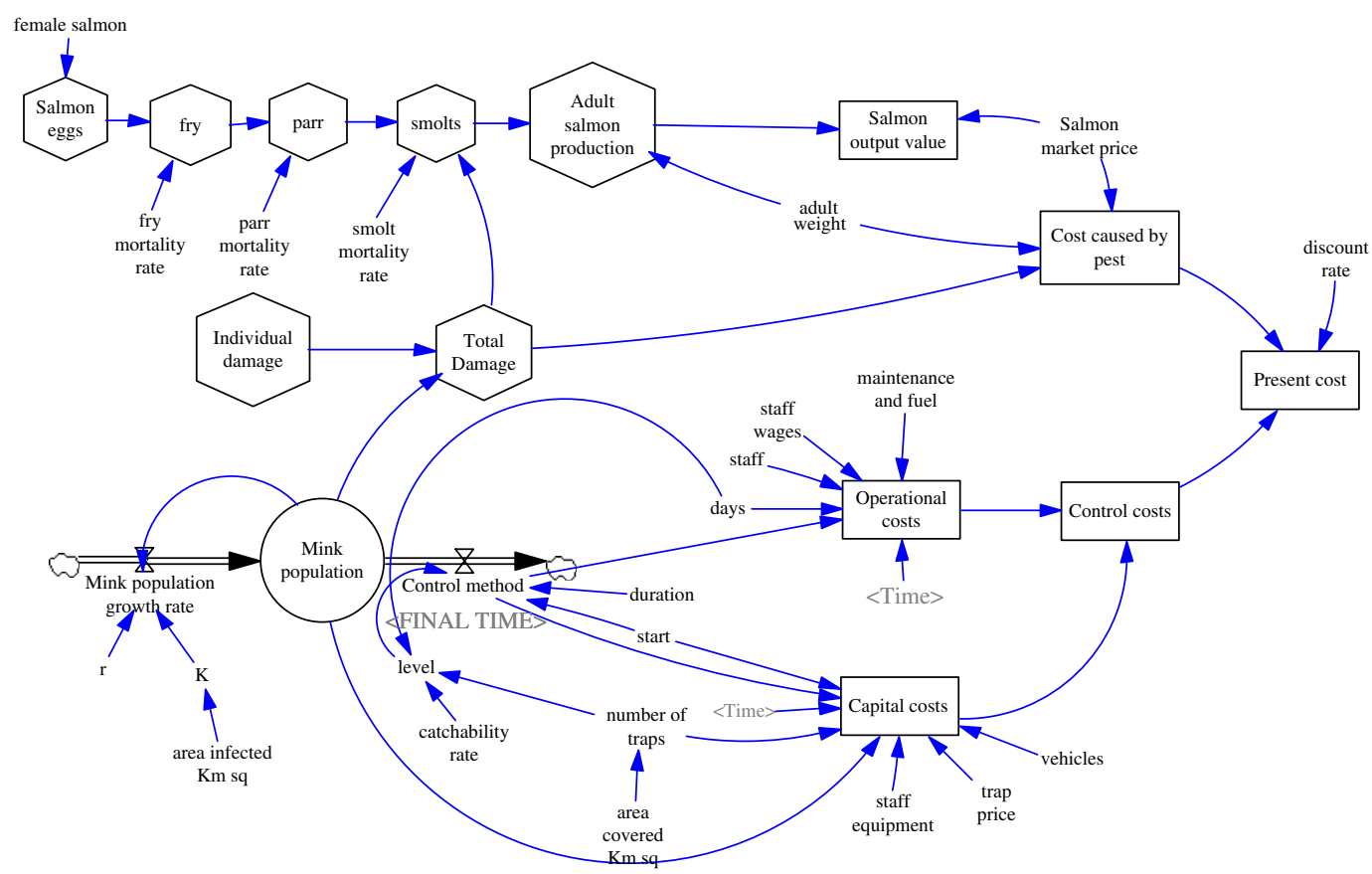

Figure 3: Graphic description of the model.

$$
\frac{\mathrm{d} y}{\mathrm{~d} t}=y(\gamma-\delta x)
$$

where eqns (1) and (2) describe the growth of prey $(x)$ and predator $(y)$ populations over time $(t)$ being $a, \beta, \gamma$ and $\delta$ are parameters that represent the interaction between species. This is mainly because the salmon population is a fixed resource. Prey densities are a predictable resource because the fish farm manager predetermines the fish population in the cage at the beginning of the cycle. He or she decides on how many fish can be reared in a cage, and this decision buffers the relatively small effects of the environment. In addition, the data used here are based on empirical dietary studies of mink on the western isles and the proportion of fish in their diet.

The output of the model is the annual level of mink populations and the damage associated with the fish farm, as well as the annual costs of the control method chosen by the fish farm. These results are used to obtain standard profitability indicators of alternative control strategies for the fish farm such as net present value (NPV) and internal rate of return (IRR). The NPV is defined as:

$$
\mathrm{NPV}=\sum_{t=0}^{t=T} \frac{B_{t}-C_{t}}{(1+r)^{t}}
$$

where $B_{t}$ is the benefit of the damage avoided associated with the control strategy in period $t ; C_{t}$ is the cost associated with the control strategy in period $t ; T$ is usually the total number of years for the 
project. Since in this study posterior economic effects to the end of the project exist they are also taken into account by choosing a longer time period $T$ (i.e. 30 years); $r$ is the discount rate.

An alternative profitability indicator is the IRR, which is defined as:

$$
\mathrm{NPV}=\sum_{t=0}^{t=T} \frac{B_{t}-C_{t}}{(1+\mathrm{IRR})^{t}}=0
$$

IRR is the interest rate that would equalise benefits and costs. Therefore an IRR higher than the interest rate shows that the investment is 'worthy'.

\subsection{Parameterisation of the farmed salmon production system}

We assume a fish farm with an annual production capacity of 400-600 tonnes of salmon. Variation is due to the fact that mortality rates and number of eggs produced may vary annually.

Wild salmon have a life cycle different to that in farmed salmon. Figure 2 shows the farmed salmon life cycle. The number of eggs produced by each female varies between 4500 and 5200 [33]. A typical fish farm producing around 400-500 tonnes of salmon will use the eggs from approximately 50 females every year. Eggs are collected for fertilising and fry are reared indoors $\left(10000 / \mathrm{m}^{2}\right)$ until they grow to a weight of $0.15-0.23 \mathrm{~g}$. Mortality of approximately $10-15 \%$ occurs during this stage of the process. During the next stage (i.e. parr) young fish are put in large indoor tanks and grow to 5-10 g (survival rate of 80-90\%). Once the parr turn to smolts they are reared outdoors in fresh water, thus becoming vulnerable to mink predation. When smolts reach $150 \mathrm{~g}$ they are transferred to sea cages where they mature for about 1 year until they reach between 2.5 -and $4 \mathrm{~kg}$, at which point the cages are put into offshore marine fisheries for another year before harvesting.

The mink population dynamics is assumed to follow a logistic function as in eqn (5).

$$
\frac{\partial M}{\partial t}=r M\left(1-\frac{M}{K}\right)
$$

where $M$ is the mink population, the constant $r$ is the intrinsic rate of increase and $K$ the carrying capacity. The intrinsic rate may vary between 0.38 and 0.46 based on work by Clode et al. [34], and the carrying capacity is $1.6 \mathrm{mink} / \mathrm{km}^{2}$.

A mink can eat approximately $75 \mathrm{~g}$ of food per day. Based on Heylar [17] it is assumed that up to $16 \%$ of the annual mink diet is salmon from a fish farm. This means a mink can eat $4380 \mathrm{~kg}$ of fish per year. The damage that mink can cause to the salmon production will depend on the availability of the fish. Fish are at their most vulnerable between November and February when the mean water temperature of approximately $8^{\circ} \mathrm{C}$ reduces their mobility [28, 35]. However, only salmon of up to $1 \mathrm{~kg}$ are vulnerable to mink predation. We assume a triangular distribution for the weight of smolts with minimum, most likely and maximum values of 20,60 and $150 \mathrm{~g}$ respectively (Table 2).

\subsection{Management strategies}

Economic theory provides us with the answer to the question of which management strategy should be chosen by the fish farm. An optimal level of mink control will be the one where the marginal costs associated with mink control (MC) are the same as the marginal damage avoided to the fish farm by implementing mink control (MB). However, as shown below, a key point in our analysis is that the 
costs associated with culling each mink are constant. A fish farm manager only takes into account the direct costs associated with his or her own production loss and does not include in this decision any other costs that the mink may cause such as ecological damage to other species. Fish farm benefits associated with the avoidance of damage by incrementally culling an increasing number of mink also remain constant since the production loss associated with mink is assumed to be linear. In this case there are two extreme possible courses of action mink eradication or 'doing nothing'. If $\mathrm{MB}>\mathrm{MC}$ we expect the fish farm to carry out control until the mink population is eradicated. If $\mathrm{MB}<\mathrm{MC}$ then 'doing nothing' would be the preferred option by the fish farm. In the model we consider four pest management strategies: (1) no control measures are in place (baseline); (2) culling at a fixed rate; (3) culling periodically; and (4) eradication.

1. No control measures are in place. In this case there are no costs associated with control measures and the fish farm will bear all the costs caused by mink predation on smolts.

2. Culling at a fixed rate. This option consists of conducting a culling programme for a fixed period of time that is long enough to reduce mink population but does not eradicate it. We run the model for a 7-year culling programme.

3. Culling periodically. This option involves conducting a repeated culling programme for a fixed period on several occasions during the 30 year scenario or until the mink population is eradicated, although eradication is not the objective.

4. Eradication. This consists in carrying out culling until the mink population is perceived to be eradicated. We add a sub-scenario within this one where after 'perceived eradication' is achieved the mink population is allowed to recover. This scenario allows evaluating the consequences of underestimation of the total area occupied by mink (i.e. the total initial mink population).

Although option 2 is clearly not supported by the economic theory as optimal it is included in the analysis in order to validate the results.

The expected catchability rate used in this analysis is 0.0028 per trap per day based on experience in the Western Isles [36].

\subsection{Economic benefits and costs}

The benefits and costs associated with each of the pest management strategies ultimately depend on a number of key variables such as the size of the mink population, price of farmed salmon and the damage caused to the fish farm in terms of number of smolts killed by the pest, which in turn depend on the control strategy, level of salmon production and duration of the strategy. Benefits were defined as the reduction in the economic damage caused by the mink population to the fish farm by implementing a mink control strategy. Environmental benefits were not included in the monetary valuation of the mink control options as the analysis is applied from the economic perspective of the fish farm.

The main components of the private economic cost to the fish farm are the loss of salmon production caused by the mink and the costs of carrying out any control strategy. The costs for the loss of production are the potential market value that the smolts would have if they became adult salmon. Costs associated with mink control can be divided into capital costs (i.e. fixed costs that are required as an initial expenditure at the start of control operations) and operational costs (i.e. costs that are incurred throughout the project lifespan). Capital costs include the number of traps and other equipment whereas operational costs include staff wages, maintenance and fuel. Traps cost approximately $£ 12$ each and are assumed to be placed at a density of 5 per $\mathrm{km}^{2}$ of the area covered by the control scheme. The analysis assumes an area affected by mink of $30 \mathrm{~km}^{2}$ and an area covered by any 
Table 3: Costs, personnel and equipment associated with control strategy.

\begin{tabular}{lr}
\hline Large vehicle $(4 \times 4)^{*}$ & 16000 \\
Small car* & 10000 \\
Quad* & 4000 \\
Boat* & 10000 \\
Maintenance & 5000 \\
Fuel & 5000 \\
Staff & 2 \\
Wage (£ per day) & 46 \\
Number worked days per year & 108 \\
Rigid trap* & 12 \\
Number of traps $\left(5 \mathrm{~km}^{2}\right)$ & 25 \\
Other equipment per person & 600 \\
\hline
\end{tabular}

*Costs only in year 1

control scheme of $5 \mathrm{~km}^{2}$. Although many fish farms will already have the vehicles required to carry out control strategies, costs of vehicles were also included as were personal equipment (e.g. water proof clothing and boots, walking boots, lifejacket, rucksack) (Table 3). Two staff are involved in placing and checking the traps in the covered area for a total of 108 days per year. This excludes the period from May to July when mink are confined to areas in and around their breeding dens and are not trappable through conventional trapping [18].

Total benefits and costs are linear functions (i.e. the costs associated with control measures and their consequent benefits increase or decrease at a constant rate with respect to the number of mink culled). In addition, in order to address the need for discounting when comparing benefits and costs over time we used a discount rate to discount all future values and derive their present values.

Figure 3 shows the model conceptualisation, which consists of a production system (i.e. salmon farm), an ecological system and a management system (i.e. mink control method). The ecological and economic parameters assumed in this model are shown in Table 2.

The model was run to simulate the alternative control strategies and compare their economic viability by applying a CBA. Decision criteria for identification of the best control option were based on NPV and IRR. The NPV of each control strategy is defined as the difference between the discounted present value of the future benefits of avoiding damage and the discounted present value of the future costs associated with the control strategy. Thus, NPV calculates the present value of a future stream of net income. Benefits for each strategy were obtained as the difference between the economic damage caused by the mink under no mink control and under the other control strategies examined. A positive (negative) NPV tells us that the control strategy benefits are greater (smaller) than its costs. When comparing different strategies the higher the NPV the better. Uncertainty about the value of a number of elements in our model such as salmon mortality rates at different life stages, some components of the operational costs (e.g. maintenance and fuel, staff wages), salmon market price and mink damage was tackled by assigning distribution functions to these variables (Table 2). Simulations and sensitivity analyses were conducted to evaluate the effect of changes in salmon price, area affected by mink and catchability rates. Simulations were carried out using two mink intrinsic rates, 0.38 and 0.46 . 


\section{RESULTS}

Results show that eradication is the optimal long-term option for a fish farm being affected by predation from a population of mink, which is in concordance with economic theory. Figure $4 \mathrm{a}-\mathrm{f}$ shows the mink population dynamics, economic damage caused by the mink and the NPV over time for the alternative control strategies using $2.5 \%$ discount rate. Mink eradication can be achieved in 11 years if mink growth intrinsic rate of increase is at 0.38 or 15 years if mink growth intrinsic rate is at 0.46 when culling is conducted continually. This period is longer if culling is not conducted continually but only periodically. If eradication is erroneously perceived to be achieved but is not, then a mink population will reach its carrying capacity in approximately 16 years if no control measures are put in place.

Analysis of the NPV for the different mink control strategies indicates that 'doing nothing' is the 'best' option up to year 14 (17) assuming a mink growth intrinsic rate of increase of $0.38(0.46)$. Mink culling starts to become economically advantageous option only after this period (Fig. 4e-f).

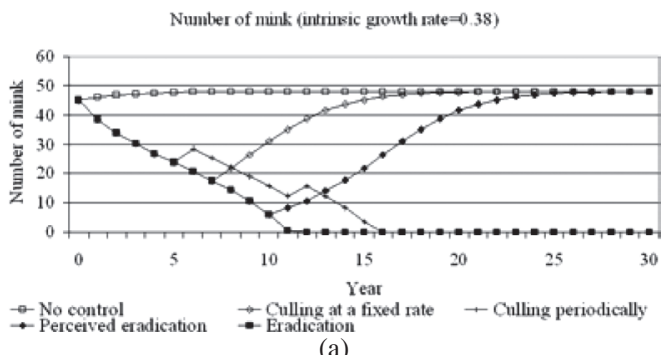

(a)

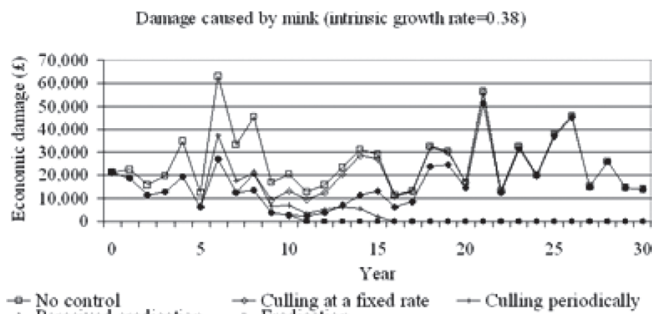

(c)

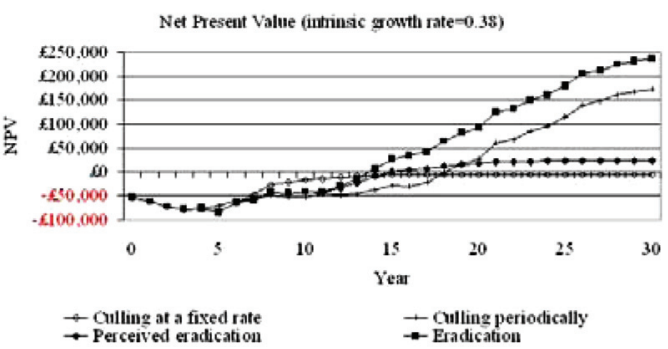

(e)

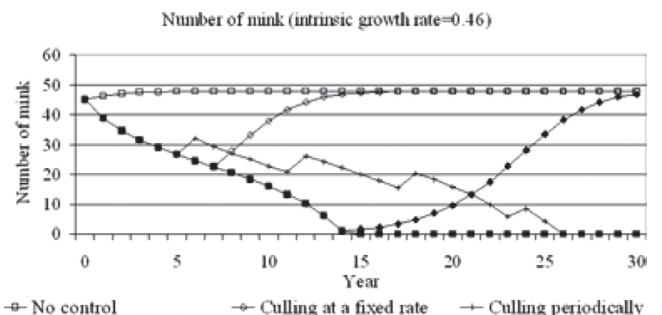

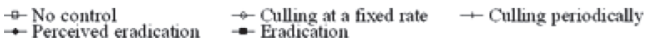

(b)

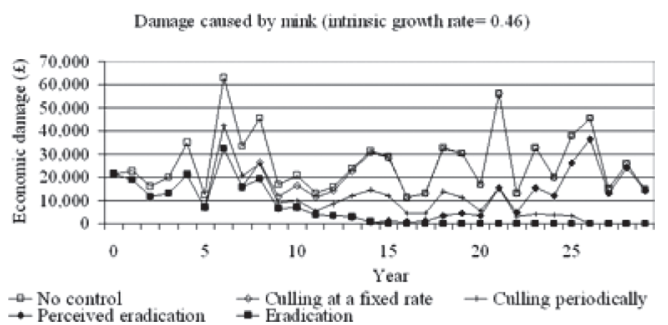

(d)

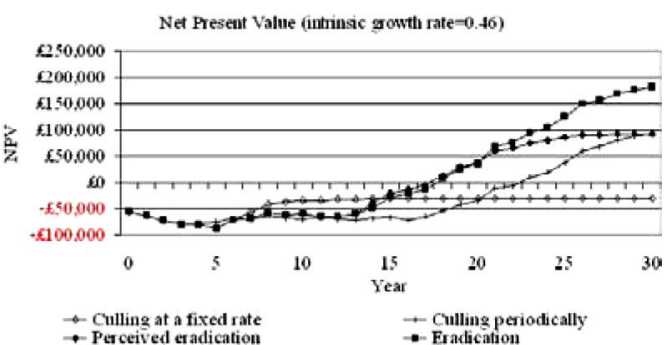

(f)

Figure 4: Number of mink for intrinsic growth rates (a) 0.38 and (b) 0.46 . Cost damage caused by mink for intrinsic growth rates (c) 0.38 and (d) 0.46 . Net Present Value for intrinsic growth rates (e) 0.38 and (f) 0.46 . 
Table 4: Internal Rate of Return for alternative control strategies.

\begin{tabular}{lrc}
\hline Intrinsic growth rate & 0.38 & 0.46 \\
\hline Culling at a fixed rate & $2 \%$ & $-4 \%$ \\
Culling periodically & $9 \%$ & $6 \%$ \\
Perceived eradication and recovery & $5 \%$ & $7 \%$ \\
Eradication & $11 \%$ & $9 \%$ \\
\hline
\end{tabular}

This is a common feature in any project where the initial capital has to be invested (i.e. capital costs) to start running the control programme and the costs of running the programme (i.e. operational costs) will pay off in a number of years. A control programme using a fixed rate culling strategy also becomes a more attractive option than eradication for a few years after the end of a chosen programme. However, as mink populations regain carrying capacity this option becomes less economically viable. The 'periodic culling of mink until the mink population is eradicated' option is not an optimal option since it delays eradication of mink and increases the damage to the fish farm over time (Fig. 4a-f).

Table 4 shows the IRR for the alternative mink control strategies by intrinsic growth rate. Eradication is the best control option in terms of IRR even at discount rates below $11 \%$ as Table 4 shows. The worst option would be to conduct a culling programme for a short fixed period of time, which allows mink population to recover.

It is expected that the pest control manager will face uncertainty about the total area that is affected by mink. The consequences of overestimating the actual population of mink have been shown above under what we called 'perceived eradication'.

\subsection{Sensitivity analysis and simulations}

Sensitivity analysis is a simple process of establishing the extent to which the results of the CBA are sensitive to the values of the inputs used in the analysis. We conducted a sensitivity analysis to investigate how the uncertainty on the area affected, which determines the total mink population the market price and the expected mink catchability rate may affect the NPV. In addition, for each of these model inputs we calculated the value which makes the NPV zero (i.e. a turning point value for deciding whether to conduct or not the mink control strategy) for each of these 'uncertain' variables through simulations. Consequently, we can put in the picture the chances that the control strategy becomes not economically viable. The input values chosen are the initial information of the model used in this study; the value below which the control strategy becomes not economically viable and a value between these two. This type of analysis helps to select the best strategy (i.e. 'eradication' or 'no control') under different values for these uncertain variables.

We use a simulation approach to investigate the interesting case of the pest control manager estimating a population of 48 mink but the real number is another between 16 and 48 (i.e. the manager overestimated the mink population) holding the current salmon market price and the catchability rate. The pest control manager will plan to conduct an eradication programme for 12 years which will cost $£ 180000$ thinking the mink population is 48 mink (i.e. the area affected is $30 \mathrm{~km}^{2}$ ). Obviously, the net benefits of the programme vary depending on the extension of the area infected and also on the accuracy with which the pest control manager has estimated the extension of the area infected. Figure 5a shows the results of the simulations for affected areas of 10, 20 and $30 \mathrm{~km}^{2}$. 


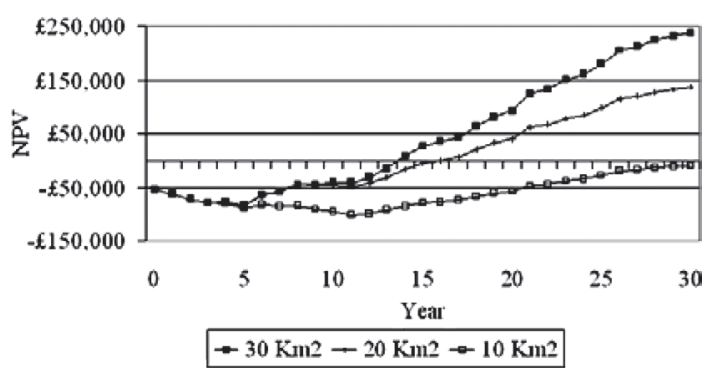

(a)

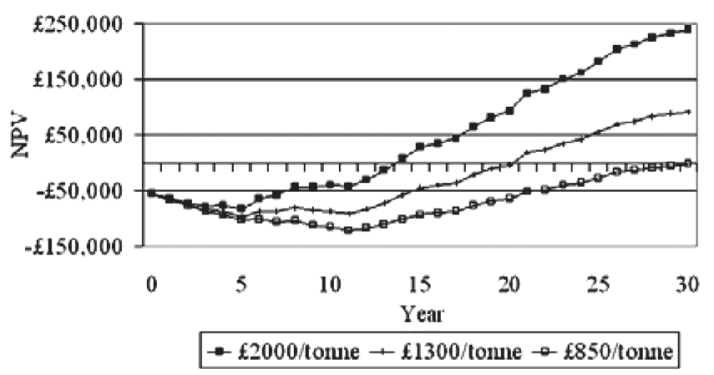

(b)

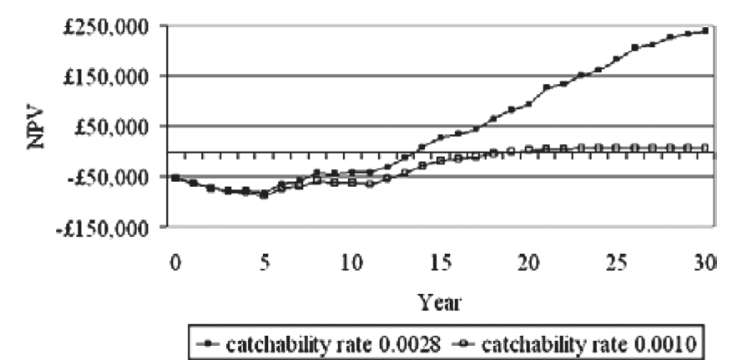

(c)

Figure 5: Simulations for (a) area infected, (b) farmed salmon price and (c) mink catchability rate.

If the pest control manager decides to carry out the eradication programme overestimating the mink population at least three times the size of the actual area affected (i.e. the manager believes the area infected is $30 \mathrm{~km}^{2}$ when actually it is $10 \mathrm{~km}^{2}$ ), the manager's decision would be economically unviable (see Fig. 5a NPV for $10 \mathrm{~km}^{2}$ ). This is the same as saying that there is a minimum number of mink population under which the predator control strategy should not be carried out. In this case such number is 16 mink (i.e. an approximate affected area of $10 \mathrm{~km}^{2}$ ).

Another key variable in the model is the market price for farmed salmon. We use a simulation to explore the impact of different market prices for farmed salmon on the NPV of a 12-year eradication programme. Simulation results suggest that for salmon market prices lower than $£ 850 /$ tonne the best option would be 'doing nothing' (Fig. 5b) or to extend the time scale of the control programme. Currently, the markets for farmed salmon are well above this figure and the current trend for farmed salmon prices suggests that such low prices are too unrealistic to be considered. 


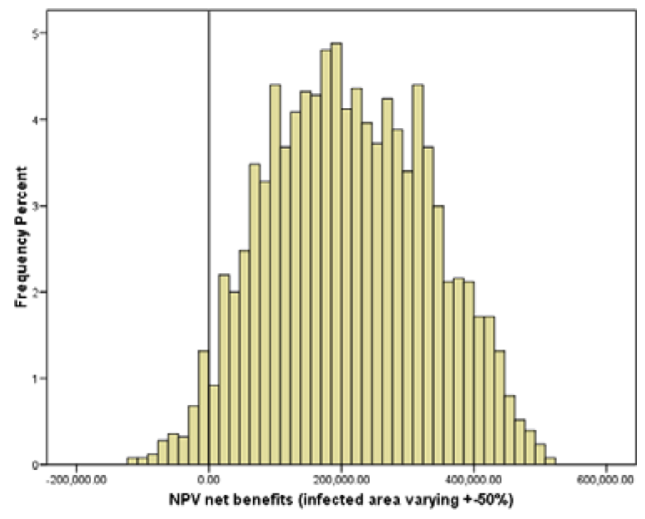

(a)

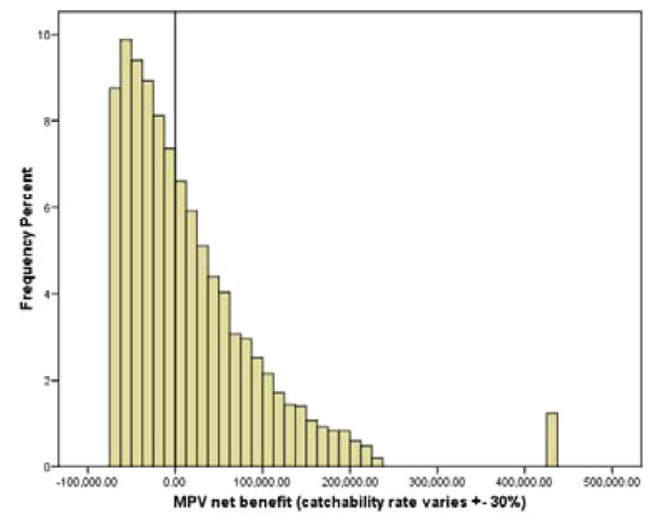

(c)

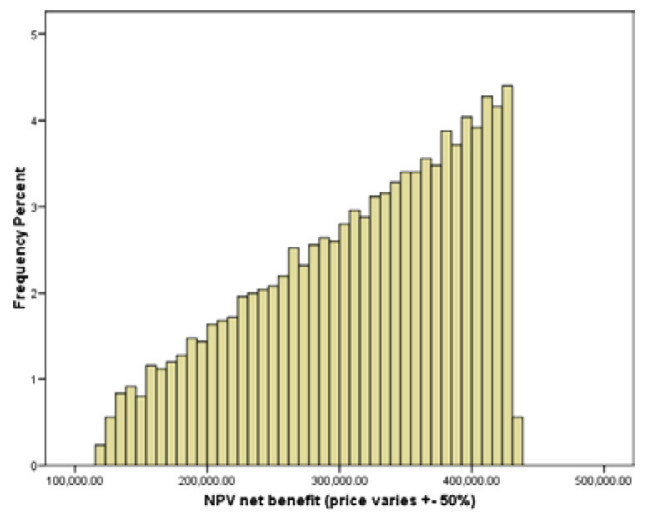

(b)

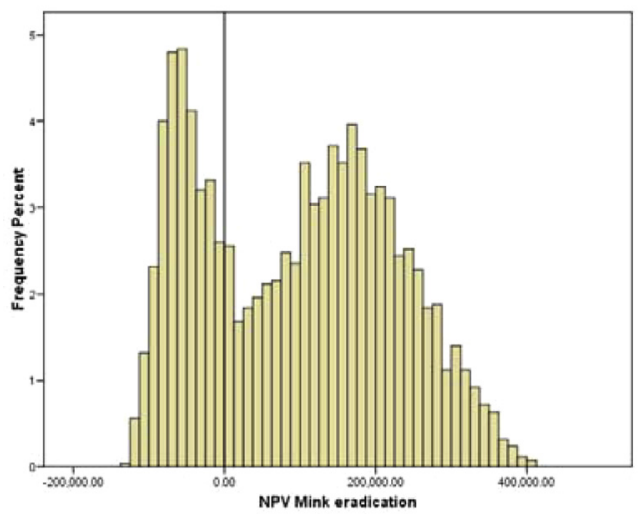

(d)

Figure 6: Net Present Value (NPV) sensitivity analysis on changes in (a) infected area, (b) farmed salmon price, (c) catchability rates and (d) 'overall' NPV sensitivity analysis on changes in infected area, farmed salmon price and catchability rates.

Finally, the expected mink catchability rate is not certain and the consequences of small changes may lead to situations where the mink population is not eradicated during the time of the programme with the possible associated consequences of a mink population recovery. In this study we have taken the value of 0.0028 mink per trap per day. When calculating the mink catchability rate value at which NPV becomes zero we found it to be 0.0025 mink per trap per day, approximately $11 \%$ lower than the value used in the model. Figure $5 \mathrm{c}$ shows the economic effects of different expected catchability rates on the NPV of a 12 -year eradication programme. For catchability rates below 0.0025 mink per trap per day the programme becomes economically unviable.

Sensitivity analysis on the NPV of the mink eradication strategy with a time scale of 30 years was conducted by allowing catchability rate, area infected and market price for farmed salmon to vary following triangular distributions. A triangular distribution describes a situation where the researcher is confident about a minimum, a maximum value and a most likely value to occur for the variable selected. Thus, the area infected was allowed to vary $\pm 30 \%$ from the initial and most likely value of $30 \mathrm{~km}^{2}$; market price for salmon was allowed to vary $\pm 50 \%$ by following a triangular distribution 
with a most likely value of $£ 2000 /$ tonne; and the catchability rate was set to follow a triangular distribution with a most likely value of 0.0028 , which is the same value found in the project to eradicate mink from Harris and the Uists, therefore we are less uncertain about this value and therefore we set $\mathrm{a} \pm 30 \%$ of 0.0028 mink per trap per day range [30].

Figure 6a-c shows the probability distribution of the NPV of implementing the mink eradication project for 11 years allowing variation for each of the three model parameters (i.e. infected area, farmed salmon price and catchability rate) whereas Fig. $6 \mathrm{~d}$ shows the sensitivity analysis results for all variation of the parameters combined. Results below suggest that amongst the parameters studied catchability rate is the most important factor in the 'overall' NPV results (Fig. 6d). In fact, for very low catchability rates the eradication strategy becomes economically unappealing (i.e. $\mathrm{NPV}<0$ ). By only allowing catchability rate to vary $36 \%$ simulations show a negative net benefit. Therefore, the catchability rate is a key parameter in deciding the sign of the NPV for mink eradication. As Fig. 5c suggests catchability rates below 0.001 mink per trap per day holding price at $£ 2000$ and infected area $30 \mathrm{~km}^{2}$ will make the mink eradication likely to be economically unviable. Only $3 \%$ of the simulations conducted in the sensitivity analysis allowing the area infected show a negative NPV whereas none of them shown a negative NPV when farmed salmon price was allowed to vary.

When all parameters are allowed to vary at the same time only $13 \%$ of the 2500 simulations conducted in our sensitivity analysis show a negative net benefit (Fig. 6d). This suggests that mink eradication should be conducted unless in those cases where catchability rate is very low, the manager overestimates the area infected and for extremely low market price for farmed salmon (lower than $50 \%$ current price).

\section{DISCUSSION AND CONCLUSIONS}

This study shows the usefulness of interdisciplinary modelling to make decisions under a suite of different ecological and economic environments. A simulation approach was applied to evaluate alternative control strategies for mink populations affecting farmed salmon. Our results are consistent with economic theory, which identifies two possible outcomes under linear cost and benefit functions, either 'doing nothing' or eradication. A pest control manager's accuracy in estimating the impacts of a problem, i.e. the area affected by mink, farmed salmon price and the time scale chosen are key variables in deciding which option is best from an economic point of view. It is therefore crucial to obtain accurate and reliable information on variables such as area affected, total mink population, future farmed salmon prices, expected mink catchability rates and mink intrinsic rates before designing and putting in place a mink control programme. Clearly there will always be a level of uncertainty about the real values of these variables, especially due to their variation over time. Despite this problem it is possible to identify the critical values under which the pest control manager would take the wrong decision. Time is also a crucial variable in deciding which strategy to chose. If the analysis had been applied for a short time scale, it would have led to the model recommending a control strategy that would have been viewed as sub-optimal in a longer-term study.

The fish farm-mink control scenarios explored in this study were used to explore the effectiveness of different strategies in the face of varying external factors such as the price of fish. In reality mink control has many benefits that cannot be truly separated from this system. Mink predate on ground nesting bird populations [37-39], which in turn influence eco-tourism levels on the Western Isles [32].

\section{ACKNOWLEDGEMENTS}

This study is based on previous work funded by DEFRA. We thank Dr Keith Walters for his support, comments and suggestions to this paper. We also thank two anonymous referees for their valuable comments. 


\section{REFERENCES}

[1] Atkinson, IAE., Introductions of wildlife as a cause of species extinctions. Wildlife Biology, 2, pp. 135-141, 1996.

[2] Vitousek, P.M., D’Antonio, C.M., Loope, L.L., Rejmanek, M. \& Westbrooks, R., Introduced species: a significant component of human-caused global change. New Zealand Journal of Ecology, 21, pp. 1-16, 1997.

[3] Perrings, C., Williamson, M., Barbier, E.B., Delfino, D., Dalmazzone, S., Shogren, J., Simmons, P. \& Watkinson, A., Biological invasion risks and the public good: an economic perspective. Conservation Ecology, 6(1): art. no 1, 2002.

[4] Shogren, J.F. \& Tschirhart, J., Integrating ecology and economics to address bioinvasions. Ecological Economics, 52(3), pp. 267-271, 2005.

[5] VanVuren, D. \& Smallwood, K.W., Ecological management of vertebrate pests in agricultural systems. Biological Agriculture and Horticulture, 13, pp. 39-62, 1996.

[6] Mumford, J.D. \& Norton, G.A., Economics of decision making in pest management. Annual Review of Entomology, 29, pp. 157-174, 1984.

[7] Baxter, P.W.J., Sabo, J.L., Wilcox, C., McCarthy, M.A., \& Possingham, H.P., Cost-effective suppression and eradication of invasive predators. Conservation Biology, 22, pp. 89-98, 2008.

[8] Bicknell, K., Cost-benefit and cost-effectiveness analyses in pest-management. New Zealand Journal of Zoology, 20, pp. 307-312, 1993.

[9] Moberly, R.L., White, P.C.L., Webbon, C.C., Baker, P.J., \& Harris, S., Modelling costs of fox predation and preventative measures on sheep farms in Britain. Journal of Environmental Management, 70, pp. 129-143, 2004.

[10] Frederiksen, M., Lebreton, J.D., \& Bregnballe, T., The interplay between culling and densitydependence in the great cormorant: a modelling approach. Journal of Applied Ecology, 38, pp. 617-627, 2001.

[11] Western Isles Fisheries Trust, Biennial Report, 1999.

[12] Edwards, T. \& Cook, G., Aquaculture, The Scottish Parliament, Research Note RN 01/103, 2001.

[13] Cuthbert, J.H., The origin and distribution of feral mink in Scotland. Mammal Review, 3, pp. 97-103, 1973.

[14] Angus, S., A proposed mink control programme. Hebridean Naturalist, 11, pp. 78-84, 1992.

[15] Moore, N.P., Roy, S.S. \& Heylar, A., Mink eradication project ground nesting birds in the Western Isles, Scotland, UK. New Zealand Journal of Zoology, 30, pp. 443-452, 2003.

[16] Bonesi, L., Harrington, L.A., Maran, T., Sidorovich, V.E. \& Macdonald, D.W., Demography of three populations of American mink, Mustela vison, in Europe. Mammal Review, 1, pp. 98-106, 2006.

[17] Helyar, A.F., The ecology of American mink (Mustela vison); response to control, PhD Thesis, Department of Biology, University of York, 2005.

[18] Dunstone, N., The Mink.T. and A.D. Poyser Limited: London, 235 pp., 1993.

[19] Akande, M., The food of feral mink (Mustela vison) in Scotland. Journal of Zoology, 167, pp. 475-479, 1972.

[20] Day M.G. \& Linn I., Notes on the food of feral mink Mustela vison in England and Wales. Journal of Zoology, 167, pp. 463-473, 1972.

[21] Arnold, T.W. \& Fritzell, E.K., Food habits of prairie mink during the waterfowl breeding season. Canadian Journal of Zoology, 65, pp. 2322-2324, 1987.

[22] Strachan, C. \& Jefferies, D.J., An assessment of the diet of feral American mink Mustela vison from scats collected in areas where water voles Arvicola terrestris occur. Naturalist 121, pp. 73-81, 1996. 
[23] Ferreras, P. \& Macdonald, D.W., 1999. The impact of American mink Mustela vison on water birds in the Upper Thames. Journal of Applied Ecology, 36, pp. 701-708, 1999.

[24] Macdonald, D.W. \& Strachan, R., The Mink and the Water Vole: Analyses for Conservation, George Street Press: Stafford, 1999.

[25] Macdonald, D.W., Sidorovich, V.E., Anisomova, N.V., Sidorovich, N.V. \& Johnson, P.J., The impact of American mink Mustela vison and European mink Mustela lutreola on water voles Arvicola terrestris in Belarus. Ecography, 25, pp. 295-302, 2002.

[26] Bartoszewicz, M. \& Zalewski, A., American mink, Mustela vison, diet and predation on waterfowl in the Slonsk Reserve, western Poland. Folia Zoologica, 52, pp. 225-238, 2003.

[27] Gerell, R., Food selection in relation to habitat in mink (Mustela vison Schreber) in Sweden. Oikos, 18, pp. 233-246, 1967.

[28] Heggenes, J. \& Borgstrom, R., Effect of mink, Mustela vison Schreber, predation on cohorts of juvenile Atlantic salmon, Salmo salar L., and brown trout S. trutta L., in three small streams. Journal of Fish Biology, 33, pp. 885-894, 1988.

[29] Moore, N.P., Robertson, P.A. \& Aegerter, J.N., Feasibility Study into the Options for Management of Mink in the Western Isles, Internal Report for Scottish Natural Heritage, 2000.

[30] Roy, S.S., Mink control to protect important birds in SPAs in the Western Isles. Final Report to EU LIFE III-Nature, 2006.

[31] Moore, B., Boyns, N., Tilley, H. \& Bostcok, J., The economic impact of Scottish salmon farming, Economic Research Paper, Number 7, The Scottish Office, 1999.

[32] Roberts, D., Thomson, K.J. \& Snowdon, P., Modelling the Western Isles Economy: Regional Accounts 1997, Final report, Macaulay Land Use Research Institute with the University of Aberdeen, 1999.

[33] Willoughby, S., Manual of Salmonid Farming. Blackwell Science: Berlin, Germany, 1999.

[34] Clode, D., Haliwell, E.C. \& MacDonald, D.W., A comparison of body condition in riverine and coastal mink (Mustela vison). Journal of Zoology, 237, pp. 686-689, 1995.

[35] Lindstrom, J.W. \& Hubert, W.A., Mink predation on radio-tagged trout during winter in a low-gradient reach of a mountain stream, Wyoming. Western North American Naturalist, 64, pp. 551-553, 2004.

[36] Roy, S., Macleod, I. \& Moore, N., The use of scent glands to improve the efficiency of mink Mustela vison captures in the Outer Hebrides. New Zealand Journal of Zoology, 33, pp. 267-271, 2006.

[37] Clode, D. \& MacDonald, D.W., Invasive predators and the conservation of island birds: the case of American Mink Mustela vison and terns Sterna spp. in the Western Isles, Scotland. Bird Study, 49, pp. 118-123, 2002.

[38] Nordstrom, M. \& Korpimaki, E., Effects of island isolation and feral mink removal on bird communities on small islands in the Baltic Sea. Journal of Animal Ecology, 73(3), pp. 424-433, 2004.

[39] Nordstrom, M., Laine, J., Ahona, M. \& Korpimaki, E., Reduced nest defence intensity and improved breeding success in terns as responses to removal of non-native American mink. Behavioural Ecology and Sociobiology, 55(5), pp. 454-460, 2004. 